Open Access

\title{
High-quality permanent draft genome sequence of the Lebeckia - nodulating Burkholderia dilworthii strain WSM $3556^{\top}$
}

Sofie E. De Meyer ${ }^{1}$, Rui Tian ${ }^{1}$, Rekha Seshadri ${ }^{2}$, Natalia Ivanova ${ }^{2}$, Amrita Pati ${ }^{2}$, Victor Markowitz ${ }^{3}$, Tanja Woyke², Ron Yates ${ }^{1,4}$, John Howieson ${ }^{1}$, Nikos Kyrpides ${ }^{2,5}$ and Wayne Reeve ${ }^{1 *}$

\begin{abstract}
Burkholderia dilworthii strain WSM3556 ${ }^{\top}$ is an aerobic, motile, Gram-negative, non-spore-forming rod that was isolated from an effective $\mathrm{N}_{2}$-fixing root nodule of Lebeckia ambigua collected near Grotto Bay Nature Reserve, in the Western Cape of South Africa, in October 2004. This plant persists in infertile and deep sandy soils with acidic $\mathrm{pH}$, and is therefore an ideal candidate for a perennial based agriculture system in Western Australia. WSM3556 ${ }^{\top}$ thus represents a potential inoculant quality strain for L. ambigua for which we describe the general features, together with genome sequence and annotation. The 7,679,067 bp high-quality permanent draft genome is arranged in 140 scaffolds of 141 contigs, contains 7,059 protein-coding genes and 64 RNA-only encoding genes, and is part of the GEBA-RNB project proposal.
\end{abstract}

Keywords: Root-nodule bacteria, Nitrogen fixation, Betaproteobacteria, South Africa, Lebeckia, GEBA-RNB

\section{Introduction}

Over the last decade, agricultural scientists have sought to discover perennial legumes from a wide range of natural environments to develop new plants for grazing systems [1]. It is thought that these plants might be more resilient to changing rainfall patterns, such as in the target environments of Western Australia. Here, winter rainfall has declined by $20 \%$ in the last two decades [2], although more frequent summer rainfall events have been experienced. In the fynbos biome of South Africa, several species that offer potential for domestication have been discovered $[1,3]$. These legumes are frequently nodulated by Burkholderia bacteria in the class Betaproteobacteria [3, 4]. The symbiosis between these Burkholderia and legumes from the genera Lebeckia and Rhynchosia fix atmospheric nitrogen to enable their cultivation on infertile soils [4-7]. Lebeckia ambigua is proving well adapted to Western Australia [1] because in areas where it is naturally found

\footnotetext{
* Correspondence: W.Reeve@murdoch.edu.au

${ }^{1}$ Centre for Rhizobium Studies, Murdoch University, Murdoch, Western Australia, Australia

Full list of author information is available at the end of the article
}

in South Africa the soil and climatic conditions approximate those of Western Australia.

Nodules and seeds of L. ambigua were collected in four expeditions to the Western Cape of South Africa between 2002 and 2007. The isolation of bacteria from these nodules gave rise to a collection of 23 strains that were identified as Burkholderia [3]. Unlike most of the previously studied nodulating Burkholderia strains, this South African group appears to associate with papilionoid forage legumes, rather than Mimosa species. WSM $3556^{\mathrm{T}}$ belongs to a subgroup of strains that were isolated in 2004 from nodules collected south west of Darling, in a natural rangeland site on the southern border of the Grotto Bay Nature Reserve [3]. The soil at the site of collection was deep sand with a $\mathrm{pH}$ of 6 . Burkholderia dilworthii strain WSM $3556^{\mathrm{T}}$ was isolated from those nodules and is effective at fixing nitrogen with $L$. ambigua and $L$. sepiaria. The nodules formed by these symbioses are crotaloid and indeterminate [3].

WSM $3556^{\mathrm{T}}$ thus represents a potential inoculant quality strain for L. ambigua, which is being developed as a grazing legume adapted to infertile soils that receive $250-400 \mathrm{~mm}$ annual rainfall in southern Australia and is therefore of special interest to the RNB chapter of the 


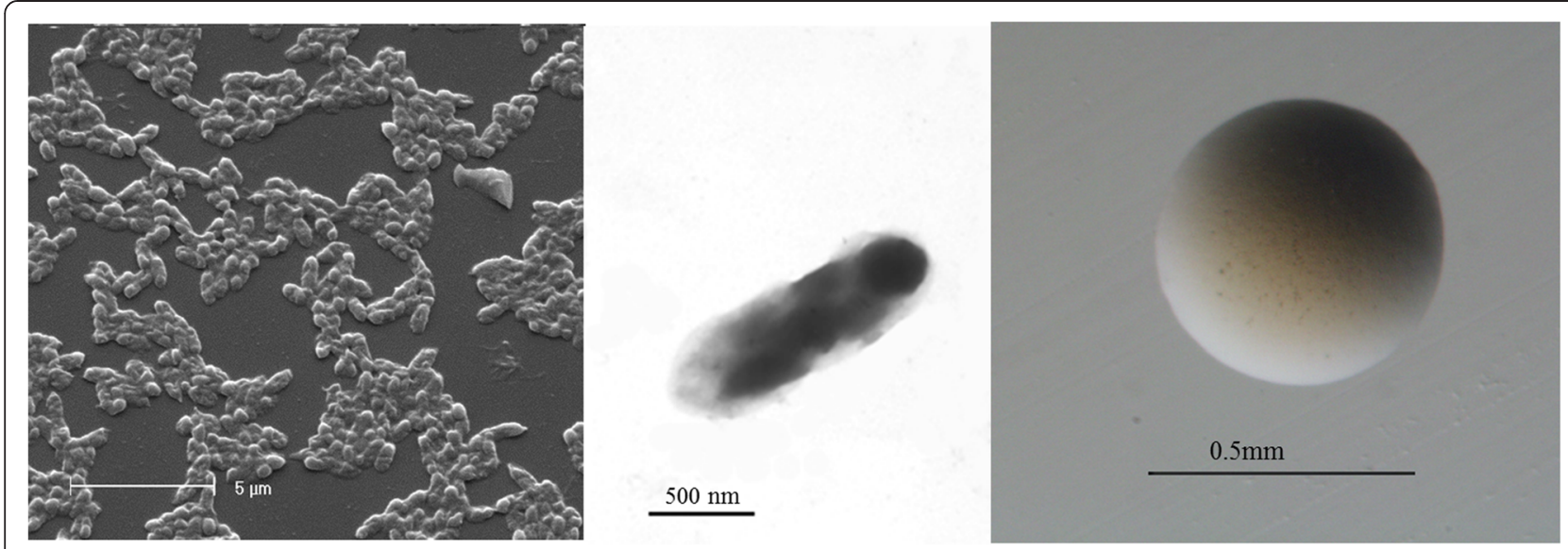

Fig. 1 Images of Burkholderia dilworthii strain WSM3556 ${ }^{\top}$ using scanning (Left) and transmission (Center) electron microscopy and the appearance of colony morphology on solid media (Right)

GEBA project. Here we present a summary classification and a set of general features for Burkholderia dilworthii strain WSM $3556^{\mathrm{T}}$ together with the description of the permanent draft genome sequence and annotation.

\section{Organism information}

\section{Classification and features}

Burkholderia dilworthii strain WSM $3556^{\mathrm{T}}$ is a motile, Gram-negative, non-spore-forming rod (Fig. 1 Left, Center) in the order Burkholderiales of the class Betaproteobacteria. The rod-shaped form varies in size with dimensions of $0.9-2 \mu \mathrm{m}$ in width and $0.4-3.0 \mu \mathrm{m}$ in length (Fig. 1 Left). It is fast growing, forming $0.4-2 \mathrm{~mm}$ diameter colonies after $24 \mathrm{~h}$ when grown on half Lupin Agar [8] and TY [9] at $28^{\circ} \mathrm{C}$. Colonies on $1 / 2 \mathrm{LA}$ are whiteopaque, slightly domed, moderately mucoid with smooth margins (Fig. 1 Right). Additional physiological properties of this strain were previously published [5].

Figure 2 shows the phylogenetic relationship of Burkholderia dilworthii strain WSM $3556^{\mathrm{T}}$ in a $16 \mathrm{~S}$ rRNA gene sequence based tree. This strain is most similar to Burkholderia rhynchosiae WSM3937 ${ }^{\mathrm{T}}$ and Burkholderia phytofirmans $\mathrm{PsJN}^{\mathrm{T}}$ based on the $16 \mathrm{~S}$ rRNA with sequence identities of $98.50 \%$ and $98.11 \%$, respectively, as determined using the EzTaxon-e server [10]. Burkholderia rhynchosiae WSM $3937^{\mathrm{T}}$ has been isolated

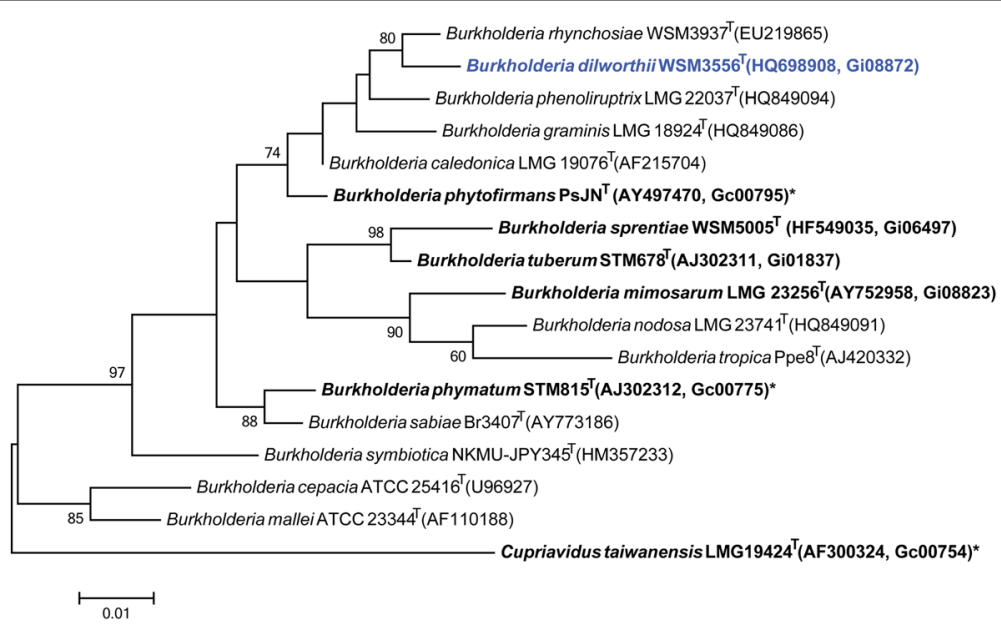

Fig. 2 Phylogenetic tree highlighting the position of Burkholderia dilworthii strain WSM3556 ${ }^{\top}$ (shown in blue print), relative to other strains in the Burkholderia genus using a 1,322 bp internal region of the $16 \mathrm{~S}$ rRNA gene. Cupriavidus taiwanensis LMG $19424^{\top}$ was used as an outgroup. All sites were informative and there were no gap-containing sites. Phylogenetic analyses were performed using MEGA, version 5.05 [31]. The tree was build using the maximum likelihood method with the General Time Reversible model. Bootstrap analysis with 500 replicates was performed to assess the support of the clusters. Type strains are indicated with a superscript T. Strains with a genome sequencing project registered in GOLD [14] are in bold print and the GOLD ID is provided after the NCBI accession number. Published genomes are designated with an asterisk 
from Rhynchosia ferulifolia, a herbaceous legume from the fynbos biome in South Africa [7]. Burkholderia phytofirmans PsJ $\mathrm{N}^{\mathrm{T}}$ was isolated from surface sterilized onion roots and has plant growth promoting properties on various plants, however it has not been reported in association with legumes [11]. Minimum Information about the Genome Sequence of WSM $3556^{\mathrm{T}}$ is provided in Table 1.

Table 1 Classification and general features of Burkholderia dilworthii WSM $3556^{\top}$ in accordance with the MIGS recommendations [32] published by the Genome Standards Consortium [33]

\begin{tabular}{|c|c|c|c|}
\hline MIGS ID & Property & Term & Evidence code \\
\hline & Classification & Domain Bacteria & TAS [34] \\
\hline & & Phylum Proteobacteria & TAS [35] \\
\hline & & Class Betaproteobacteria & TAS $[36,37]$ \\
\hline & & Order Burkholderiales & $\operatorname{TAS}[37,38]$ \\
\hline & & Family Burkholderiaceae & $\operatorname{TAS}[37,39]$ \\
\hline & & Genus Burkholderia & $\operatorname{TAS}[37,40]$ \\
\hline & & $\begin{array}{l}\text { Species Burkholderia } \\
\text { dilworthii }\end{array}$ & TAS [5] \\
\hline & & (Type) strain: WSM3556 ${ }^{\top}$ & TAS [5] \\
\hline & Gram stain & Negative & TAS [5] \\
\hline & Cell shape & Rod & TAS [5] \\
\hline & Motility & Motile & TAS [5] \\
\hline & Sporulation & Non-sporulating & TAS [39] \\
\hline & $\begin{array}{l}\text { Temperature } \\
\text { range }\end{array}$ & $15-37^{\circ} \mathrm{C}$ & TAS [5] \\
\hline & $\begin{array}{l}\text { Optimum } \\
\text { temperature }\end{array}$ & $28^{\circ} \mathrm{C}$ & TAS [5] \\
\hline & $\begin{array}{l}\text { pH range; } \\
\text { Optimum }\end{array}$ & $5.5-8 ; 7$ & TAS [5] \\
\hline & Carbon source & Large range & TAS [5] \\
\hline MIGS-6 & Habitat & $\begin{array}{l}\text { Soil, root nodule } \\
\text { on host }\end{array}$ & IDA \\
\hline MIGS-6.3 & Salinity & $0-10 \%$ & TAS [5] \\
\hline MIGS-22 & $\begin{array}{l}\text { Oxygen } \\
\text { requirement }\end{array}$ & Aerobic & IDA \\
\hline MIGS-15 & Biotic relationship & Free living, symbiotic & IDA \\
\hline MIGS-14 & Pathogenicity & Non-pathogenic & NAS \\
\hline MIGS-4 & $\begin{array}{l}\text { Geographic } \\
\text { location }\end{array}$ & South Africa & TAS [3] \\
\hline MIGS-5 & Sample collection & 2004 & TAS [3] \\
\hline \multirow{2}{*}{$\begin{array}{l}\text { MIGS-4.1 } \\
\text { MIGS-4.2 }\end{array}$} & Longitude & 18.44 & TAS [3] \\
\hline & Latitude & -33.49 & TAS [3] \\
\hline MIGS-4.4 & Altitude & 237 & IDA \\
\hline
\end{tabular}

Evidence codes - IDA: Inferred from Direct Assay; TAS: Traceable Author Statement (i.e., a direct report exists in the literature); NAS: Non-traceable Author Statement (i.e., not directly observed for the living, isolated sample, but based on a generally accepted property for the species, or anecdotal evidence). These evidence codes are from the Gene Ontology project [41]

\section{Symbiotaxonomy}

Burkholderia dilworthii strain WSM $3556^{\mathrm{T}}$ belongs to a group of Burkholderia strains that nodulate papilionoid forage legumes rather than the classical Mimosa host species (Mimosoideae) described for other Burkholderia microsymbionts [12]. Burkholderia dilworthii strain WSM $3556^{\mathrm{T}}$ was assessed for nodulation and nitrogen fixation on three separate $L$. ambigua genotypes (CRSLAM-37, CRSLAM-39 and CRSLAM-41) [3]. It could nodulate and fix effectively on CRSLAM-41 but was partially effective on CRSLAM-37 and CRSLAM-39 [3]. Moreover, WSM $3556^{\mathrm{T}}$ also nodulates and fixes nitrogen in association with Lebeckia sepiaria.

\section{Genome sequencing information \\ Genome project history}

This organism was selected for sequencing on the basis of its environmental and agricultural relevance to issues in global carbon cycling, alternative energy production, and biogeochemical importance, and is part of the Genomic Encyclopedia of Bacteria and Archaea, The Root Nodulating Bacteria chapter project at the U.S. Department of Energy, Joint Genome Institute for projects of relevance to agency missions [13]. The genome project is deposited in the Genomes OnLine Database [14] and the high-quality permanent draft genome sequence in IMG [15]. Sequencing, finishing and annotation were performed by the JGI using state of the art sequencing technology [16]. A summary of the project information is shown in Table 2.

Table 2 Genome sequencing project information for Burkholderia dilworthii WSM3556 ${ }^{\top}$

\begin{tabular}{lll}
\hline MIGS ID & Property & Term \\
\hline MIGS-31 & Finishing quality & High-quality-permanent-draft \\
MIGS-28 & Libraries used & Illumina Std \\
MIGS-29 & Sequencing platforms & Illumina HiSeq 2000 \\
MIGS-31.2 & Fold coverage & $367 \times$ Illumina \\
MIGS-30 & Assemblers & Velvet 1.1.04, ALLPATHS V.r37348 \\
MIGS-32 & Gene calling methods & Prodigal 1.4 \\
& Locus Tag & F759 \\
& Genbank ID & AWZT00000000 \\
& Genbank Date & December 12, 2013 \\
& of Release & \\
& GOLD ID & Gp0010131 \\
& BIOPROJECT & PRJNA182743 \\
MIGS-13 & Source Material & WSM3556, LMG 27173, HAMBI3353 \\
& Identifier & \\
& Project relevance & Symbiotic N 2 fixation, agriculture \\
\hline
\end{tabular}




\section{Growth conditions and genomic DNA preparation}

Burkholderia dilworthii strain WSM $3556^{\mathrm{T}}$ was grown on TY solid medium [9] for 3 days, a single colony was selected and used to inoculate $5 \mathrm{ml}$ TY broth medium. The culture was grown for $48 \mathrm{~h}$ on a gyratory shaker $(200 \mathrm{rpm})$ at $28{ }^{\circ} \mathrm{C}$. Subsequently $1 \mathrm{ml}$ was used to inoculate $60 \mathrm{ml}$ TY broth medium and grown on a gyratory shaker $(200 \mathrm{rpm})$ at $28{ }^{\circ} \mathrm{C}$ until $\mathrm{OD} 0.6$ was reached. DNA was isolated from $60 \mathrm{~mL}$ of cells using a CTAB bacterial genomic DNA isolation method [17]. Final concentration of the DNA was $0.5 \mathrm{mg} / \mathrm{ml}$.

\section{Genome sequencing and assembly}

The genome of Burkholderia dilworthii strain WSM $3556^{\mathrm{T}}$ was sequenced at the DOE Joint Genome Institute using state of the art technology [18]. For this genome, an Illumina standard shotgun library was constructed and sequenced using the Illumina HiSeq 2000 platform, which generated 9,394,768 reads totalling 2,818.4 Mbp of Illumina data. All general aspects of library construction and sequencing performed at the JGI can be found on the JGI web site [16]. All raw Illumina sequence data was passed through DUK, a filtering program developed at JGI, which removes known Illumina sequencing and library preparation artifacts (Mingkun L, Copeland A, Han J. unpublished). The following steps were then performed for assembly: (1) filtered Illumina reads were assembled using Velvet, version 1.1.04 [19], (2) 1-3 Kbp simulated paired end reads were created from Velvet contigs using wgsim [20], (3) Illumina reads were assembled with simulated read pairs using Allpaths (version r37348) [21]. Parameters for assembly steps were: 1 ) Velvet -exp_cov 90

Table 3 Genome statistics for Burkholderia dilworthii strain WSM $3556^{\top}$

\begin{tabular}{lrr}
\hline Attribute & \multicolumn{1}{l}{ Value } & \% of total \\
\hline Genome size (bp) & $7,679,067$ & 100.00 \\
DNA coding (bp) & $6,485,063$ & 84.45 \\
DNA G + C (bp) & $4,743,598$ & 61.77 \\
DNA scaffolds & 140 & 100.00 \\
Total genes & 7,123 & 100.00 \\
Protein-coding genes & 7,059 & 99.10 \\
RNA genes & 64 & 0.90 \\
Pseudo genes & 0 & 0.00 \\
Genes in internal clusters & 426 & 5.98 \\
Genes with function prediction & 5,431 & 76.25 \\
Genes assigned to COGs & 4,704 & 66.04 \\
Genes with Pfam domains & 5,730 & 80.44 \\
Genes with signal peptides & 642 & 9.01 \\
Genes with transmembrane helices & 1,585 & 22.25 \\
CRISPR repeats & 0 & 0 \\
\hline
\end{tabular}

-cov_cutoff 20 -exportFiltered yes -very_clean yes), 2) wgsim (-e 0-1 76-2 76 -r 0 -R 0 -X 0 -d 3000 -s 300 -N 1266735), 3) Allpaths-LG (PrepareAllpathsInputs: PHRED_64 $=1$ PLOIDY $=1$ JUMP_COVERAGE $=25$ FRAG_COVERAGE $=125$, RunAllpathsLG: $\quad$ RUN = $125 \mathrm{std}+25 x$ fakedpairs TARGETS $=$ standard VAPI_WARN_ ONLY $=$ True OVERWRITE $=$ True). The final draft assembly contained 141 contigs in 140 scaffolds. The total size of the genome is $7.7 \mathrm{Mbp}$ and the final assembly is based on 2,818.4 Mbp of Illumina draft data, which provides an average of $367 x$ coverage of the genome.

\section{Genome annotation}

Genes were identified using Prodigal [22], as part of the DOE-JGI genome annotation pipeline [23, 24] followed by a round of manual curation using GenePRIMP [25] for finished genomes and Draft genomes in fewer than 10 scaffolds. The predicted CDSs were translated and

Table 4 Number of genes associated with general COG functional categories

\begin{tabular}{lrrll}
\hline Code & Value & \% age & COG category \\
\hline A & 186 & 3.50 & Translation, ribosomal structure and biogenesis \\
K & 1 & 0.02 & RNA processing and modification \\
L & 528 & 9.94 & Transcription \\
B & 183 & 3.44 & Replication, recombination and repair \\
D & 1 & 0.02 & Chromatin structure and dynamics \\
& 34 & 0.64 & Cell cycle control, Cell division, chromosome \\
V & 50 & 0.94 & Defense mechanisms \\
T & 235 & 4.42 & Signal transduction mechanisms \\
M & 310 & 5.83 & Cell wall/membrane/envelope biogenesis \\
N & 92 & 1.73 & Cell motility \\
U & 133 & 2.50 & Intracellular trafficking, secretion, and vesicular \\
& & & transport \\
O & 159 & 2.99 & Posttranslational modification, protein turnover, \\
& & & chaperones \\
C & 362 & 6.81 & Energy production and conversion \\
G & 445 & 8.38 & Carbohydrate transport and metabolism \\
E & 581 & 10.94 & Amino acid transport and metabolism \\
F & 89 & 1.68 & Nucleotide transport and metabolism \\
H & 195 & 3.67 & Coenzyme transport and metabolism \\
I & 255 & 4.80 & Lipid transport and metabolism \\
P & 262 & 4.93 & Inorganic ion transport and metabolism \\
Q & 179 & 3.37 & Secondary metabolite biosynthesis, transport and \\
& & & catabolism \\
R & 600 & 11.29 & General function prediction only \\
S & 431 & 8.11 & Function unknown \\
\hline & 2419 & 33.96 & Not in CoGs \\
\hline & & & & \\
& & &
\end{tabular}

The total is based on the total number of protein coding genes in the genome 
used to search the NCBI non-redundant database, UniProt, TIGRFam, Pfam, KEGG, COG, and InterPro databases. The tRNAScanSE tool [26] was used to find tRNA genes, whereas ribosomal RNA genes were found by searches against models of the ribosomal RNA genes built from SILVA [27]. Other non-coding RNAs such as the RNA components of the protein secretion complex and the RNase $\mathrm{P}$ were identified by searching the genome for the corresponding Rfam profiles using INFERNAL [28]. Additional gene prediction analysis and manual functional annotation was performed within the Integrated Microbial Genomes-Expert Review system [29] developed by the Joint Genome Institute, Walnut Creek, CA, USA.

\section{Genome properties}

The genome is 7,679,067 nucleotides with $61.77 \%$ GC content (Table 3) and comprised of 140 scaffolds and 141 contigs. From a total of 7,123 genes, 7,059 were protein encoding and 64 RNA only encoding genes. The majority of genes $(76.25 \%)$ were assigned a putative function whilst the remaining genes were annotated as hypothetical. The distribution of genes into COG functional categories is presented in Table 4.

\section{Conclusion}

Burkholderia dilworthii WSM3556 ${ }^{\mathrm{T}}$ belongs to a group of Beta-rhizobia isolated from Lebeckia ambigua from the fynbos biome in South Africa [3]. WSM $3556^{\mathrm{T}}$ is phylogeneticaly most closely related to Burkholderia rhynchosiae WSM $3937^{\mathrm{T}}$ and Burkholderia phytofirmans PsJN ${ }^{\mathrm{T}}$. Of these strains only WSM $3556^{\mathrm{T}}$ and WSM3937 ${ }^{\mathrm{T}}$ are legume microsymbionts. Out of 13 Burkholderia strains that are known legume microsymbionts, only four

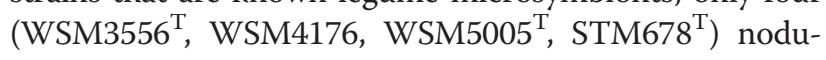
late South African papilionoid species. A comparison of these nodulating strains reveals that WSM $3556^{\mathrm{T}}$ has the smallest genome (7.7 Mbp), the smallest KOG count (1295) and the lowest GC (61.77\%) percentage in this group. These four genomes share the nitrogenase-RXN MetaCyc pathway catalyzed by a multiprotein nitrogenase complex. Strains WSM3556 ${ }^{\mathrm{T}}$, WSM4176, WSM5005 ${ }^{\mathrm{T}}$ [30] have been shown to fix nitrogen with Lebeckia ambigua provenances with varying degrees of effectiveness. WSM $3556^{\mathrm{T}}$ is partially effective on two out of three L. ambigua provenances, WSM4176 is partially effective on only one $L$. ambigua provenance and WSM $5005^{\mathrm{T}}$ is effective on all three $L$. ambigua provenances. The genome sequences of these fynbos bacteria provides an unprecedented opportunity to reveal the genetic determinants required for effective nitrogen fixation with Lebeckia.

\section{Abbreviations}

GEBA-RNB: Genomic Encyclopedia of Bacteria and Archaea - Root Nodule Bacteria; JGI: Joint Genome Institute; TY: Trypton yeast; CTAB: Cetyl trimethyl ammonium bromide; WSM: Western Australian Soil Microbiology.

\section{Competing interests}

The authors declare that they have no competing interests.

\section{Authors' contributions}

$J H$ and RY supplied the strain and background information for this project, TR supplied DNA to JGI and performed all imaging, SDM and WR drafted the paper, $\mathrm{JH}$ provided financial support and all other authors were involved in sequencing the genome and editing the final manuscript. All authors read and approved the final manuscript.

\section{Acknowledgements}

This work was performed under the auspices of the US Department of Energy Office of Science, Biological and Environmental Research Program, and by the University of California, Lawrence Berkeley National Laboratory under contract No. DE-AC02-05CH11231, Lawrence Livermore National Laboratory under Contract No. DE-AC52-07NA27344, and Los Alamos National Laboratory under contract No. DE-AC02-06NA25396.

\section{Author details}

${ }^{1}$ Centre for Rhizobium Studies, Murdoch University, Murdoch, Western Australia, Australia. ${ }^{2}$ DOE Joint Genome Institute, Walnut Creek, California, USA. ${ }^{3}$ Biological Data Management and Technology Center, Lawrence Berkeley National Laboratory, Berkeley, California, USA. ${ }^{4}$ Department of Agriculture and Food, South Perth, Western Australia, Australia. ${ }^{5}$ Department of Biological Sciences, Faculty of Science, King Abdulaziz University, Jeddah, Saudi Arabia.

Received: 26 November 2014 Accepted: 22 July 2015

Published online: 19 September 2015

\section{References}

1. Howieson JG, Yates RJ, Foster K, Real D, Besier B. Prospects for the future use of legumes. In: Dilworth MJ, James EK, Sprent JI, Newton WE, editors. Leguminous Nitrogen-Fixing Symbioses. London, UK: Elsevier; 2008. p. 363-94.

2. George R, Speed R, Simons JA, Smith RH, Ferdowsian R, Raper GP, et al. Long-term groundwater trends and their impact on the future extent of dryland salinity in Western Australia in a varibale climate. In Salinity Forum. 2008.

3. Howieson JG, De Meyer SE, Vivas-Marfisi A, Ratnayake S, Ardley JK, Yates RJ. Novel Burkholderia bacteria isolated from Lebeckia ambigua - A perennial suffrutescent legume of the fynbos. Soil Biol Biochem. 2013;60:55-64.

4. Garau G, Yates RJ, Deiana P, Howieson JG. Novel strains of nodulating Burkholderia have a role in nitrogen fixation with papilionoid herbaceous legumes adapted to acid, infertile soils. Soil Biol Biochem. 2009;41:125-34.

5. De Meyer SE, Cnockaert M, Ardley JK, Van Wyk B-E, Vandamme PA, Howieson JG. Burkholderia dilworthii sp. nov., isolated from Lebeckia ambigua root nodules. Int J Syst Evol Microbiol. 2014;64:1090-5.

6. De Meyer SE, Cnockaert M, Ardley JK, Maker G, Yates R, Howieson JG, et al. Burkholderia sprentiae sp. nov., isolated from Lebeckia ambigua root nodules. Int J Syst Evol Microbiol. 2013;63:3950-7.

7. De Meyer SE, Cnockaert M, Ardley JK, Trengove RD, Garau G, Howieson JG, et al. Burkholderia rhynchosiae sp. nov., isolated from Rhynchosia ferulifolia root nodules. Int J Syst Evol Microbiol. 2013;63:3944-9.

8. Howieson JG, Ewing MA, D'antuono MF. Selection for acid tolerance in Rhizobium meliloti. Plant Soil. 1988;105:179-88.

9. Beringer JE. R factor transfer in Rhizobium leguminosarum. J Gen Microbiol. 1974;84:188-98.

10. Kim O-S, Cho Y-J, Lee K, Yoon S-H, Kim M, Na H, et al. Introducing EzTaxon-e: a prokaryotic $16 \mathrm{~S}$ rRNA gene sequence database with phylotypes that represent uncultured species. Int I Syst Evol Microbiol. 2012;62:716-21.

11. Sessitsch A, Coenye T, Sturz AV, Vandamme P, Barka EA, Salles JF, et al. Burkholderia phytofirmans sp. nov., a novel plant-associated bacterium with plant-beneficial properties. Int J Syst Evol Microbiol. 2005;55:1187-92.

12. Elliott GN, Chou J-H, Chen W-M, Bloemberg GV, Bontemps C, Martínez-

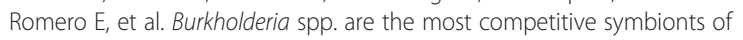
Mimosa, particularly under N-limited conditions. Environ Microbiol. 2009;11:762-78. 
13. Reeve W, Ardley J, Tian R, Eshragi L, Yoon J, Ngamwisetkun P, et al. A genomic encyclopedia of the root nodule bacteria: Assessing genetic diversity through a systematic biogeographic survey. Stand Genomic Sci. 2015;10:14.

14. Pagani I, Liolios K, Jansson J, Chen IM, Smirnova T, Nosrat B, et al. The Genomes OnLine Database (GOLD) v.4: status of genomic and metagenomic projects and their associated metadata. Nucleic Acids Res. 2012;40:D571-579.

15. Markowitz VM, Chen I-MA, Palaniappan K, Chu K, Szeto E, Pillay M, et al. IMG 4 version of the integrated microbial genomes comparative analysis system. Nucleic Acids Res. 2014;42:D560-7.

16. JGI Website. [http://www.jgi.doe.gov]

17. CTAB DNA extraction protocol. [http://jgi.doe.gov/collaborate-with-jgi/ pmo-overview/protocols-sample-preparation-information/]

18. Mavromatis K, Land ML, Brettin TS, Quest DJ, Copeland A, Clum A, et al. The fast changing landscape of sequencing technologies and their impact on microbial genome assemblies and annotation. PLoS ONE. 2012;7, e48837.

19. Zerbino D, Birney E. Velvet: algorithms for de novo short read assembly using de Bruijn graphs. Genome Res. 2008;18:821-9.

20. wgsim. [https://github.com//h3/wgsim]

21. Gnerre S, MacCallum I, Przybylski D, Ribeiro FJ, Burton JN, Walker BJ, et al. High-quality draft assemblies of mammalian genomes from massively parallel sequence data. Proc Natl Acad Sci USA. 2011;108:1513-8.

22. Hyatt D, Chen GL, Locascio PF, Land ML, Larimer FW, Hauser L. Prodigal: prokaryotic gene recognition and translation initiation site identification. BMC Bioinformatics. 2010;11:119.

23. Chen IM, Markowitz VM, Chu K, Anderson I, Mavromatis K, Kyrpides NC, et al. Improving microbial genome annotations in an integrated database context. PLOS ONE. 2013;8, e54859.

24. Mavromatis K, Ivanova NN, Chen IM, Szeto E, Markowitz VM, Kyrpides NC The DOE-JGI Standard Operating Procedure for the annotations of microbial genomes. Stand Genomic Sci. 2009;1:63-7.

25. Pati A, Ivanova NN, Mikhailova N, Ovchinnikova G, Hooper SD, Lykidis A, et al. GenePRIMP: a gene prediction improvement pipeline for prokaryotic genomes. Nat Methods. 2010;7:455-7.

26. Lowe TM, Eddy SR. tRNAscan-SE: a program for improved detection of transfer RNA genes in genomic sequence. Nucleic Acids Res. 1997;25:955-64.

27. Pruesse E, Quast C, Knittel K, Fuchs BM, Ludwig W, Peplies J, et al. SILVA: a comprehensive online resource for quality checked and aligned ribosomal RNA sequence data compatible with ARB. Nucleic Acids Res. 2007;35:7188-96.

28. INFERNAL. Inference of RNA alignments. [http://infernal.janelia.org]

29. Markowitz VM, Mavromatis K, Ivanova NN, Chen IM, Chu K, Kyrpides NC. IMG ER: a system for microbial genome annotation expert review and curation. Bioinformatics. 2009;25:2271-8.

30. Reeve W, De Meyer S, Terpolilli J, Melino V, Ardley J, Rui T, et al. Genome sequence of the Lebeckia ambigua - nodulating Burkholderia sprentiae strain WSM5005T. Stand Genomic Sci. 2013;9:385-94

31. Tamura K, Peterson D, Peterson N, Stecher G, Nei M, Kumar S. MEGA5: Molecular Evolutionary Genetics Analysis using maximum likelihood, evolutionary distance, and maximum parsimony methods. Mol Biol Evol. 2011;28:2731-9.

32. Field D, Garrity G, Gray T, Morrison N, Selengut J, Sterk P, et al. Towards a richer description of our complete collection of genomes and metagenomes "Minimum Information about a Genome Sequence" (MIGS) specification. Nat Biotechnol. 2008;26:541-7.

33. Field D, Amaral-Zettler L, Cochrane G, Cole JR, Dawyndt P, Garrity GM, et al. The Genomic Standards Consortium. PLoS Biol. 2011;9, e1001088.

34. Woese CR, Kandler O, Wheelis ML. Towards a natural system of organisms: proposal for the domains Archaea, Bacteria, and Eucarya. Proc Natl Acad Sci USA. 1990;87:4576-9.

35. Chen WX, Wang ET, Kuykendall LD. The Proteobacteria. New York: Springer - Verlag; 2005.

36. Garrity GM, Bell JA, Lilburn TE. Class II. Betaproteobacteria. In: Garrity GM, Brenner DJ, Krieg NR, Staley JT, editors. Bergey's Manual of Systematic Bacteriology. Volume 2. Secondth ed. New York: Springer - Verlag; 2005.

37. List of new names and new combinations previously effectively, but not validly, published. Int J Syst Evol Microbiol 2006, 56:1-6.

38. Garrity GM, Bell JA, Lilburn TE. Order 1. Burkholderiales. In: Garrity GM, Brenner DJ, Krieg NR, Staley JT, editors. Bergey's Manual of Systematic Bacteriology. Volume 2. Secondth ed. New York: Springer - Verlag; 2005.
39. Garrity GM, Bell JA, Lilburn TE. Family I. Burkholderiaceae. In: Garrity GM, Brenner DJ, Krieg NR, Staley JT, editors. Bergey's Manual of Systematic Bacteriology. Volume 2. Secondth ed. New York: Springer - Verlag; 2005.

40. Palleroni NJ. Genus I. Burkholderia. In: Garrity GM, Brenner DJ, Krieg NR Staley JT, editors. Bergey's Manual of Systematic Bacteriology. Volume 2. Secondth ed. New York: Springer - Verlag; 2005.

41. Ashburner M, Ball CA, Blake JA, Botstein D, Butler H, Cherry JM, et al. Gene ontology: tool for the unification of biology. The Gene Ontology Consortium Nat Genet. 2000;25:25-9.

\section{Submit your next manuscript to BioMed Central and take full advantage of:}

- Convenient online submission

- Thorough peer review

- No space constraints or color figure charges

- Immediate publication on acceptance

- Inclusion in PubMed, CAS, Scopus and Google Scholar

- Research which is freely available for redistribution 